\title{
The Views of Pre-Service Elementary Teachers About Online and Traditional Peer Assessment
}

\author{
Ahmet Oguz Akcay (iD) 1, ${ }^{*}$ Ufuk Guven (D)2, Engin Karahan (D)3 \\ ${ }^{1}$ Eskişehir Osmangazi University, Faculty of Education, Department of Elementary and Early Childhood \\ Education, Eskişehir \\ ${ }^{2}$ Düzce University, Faculty of Education, Department of Elementary and Early Childhood Education, Düzce \\ ${ }^{3}$ Eskişehir Osmangazi University, Faculty of Education, Department of Curriculum and Instruction, Eskişehir
}

\section{ARTICLE HISTORY}

Received: July 01, 2020

Revised: Feb. 16, 2021

Accepted: Apr. 09, 2021

Keywords:

Online peer assessment, Elementary Teacher Education, Traditional peer-assessment

\begin{abstract}
The goal of this study is to compare traditional peer evaluation and online peer evaluation in order to identify which method is more effective in evaluating peers. Qualitative research method was used in this study to understand pre-service teachers' opinions on different peer evaluation techniques. The study was carried out in a state university in Turkey. The sample consisted of 58 second year pre-service teachers majoring in primary school teacher program who enrolled in "Instructional Technologies and Material Development" course. Pre-service teachers were divided into 11 groups, with five or six students in each group. Participation was voluntary and the students in each group actively participated in the traditional and online peer assessment activities. The analyses of the data were done via content analysis, by creating categories and then themes. The themes that emerged as a result of the analysis of the data collected within the study were (1) objectivity, (2) evaluation criteria, (3) interaction, and (4) attributes of the online evaluation platform. The study concluded that a combination of peer and instructor evaluation and even selfassessment can give a better validity and objectivity of assessment.
\end{abstract}

\section{INTRODUCTION}

Every teaching and learning process contains a strategic assessment system because assessment is an essential part of every instructional method (Taras, 2005). Assessment informs students about their learning level and advises teachers about student performance, instructional methods, and areas where students need more help to better understand subjects (The National Council for Teacher Education [NCTE], 2013). Individual, peer or group assessment, projects, and tests often enhance the learning experiences of students. Assessment also provides feedback to students and teachers. With these feedbacks, students may correct their knowledge on a subject (Roediger et al., 2011). Moreover, teachers have an important role in organizing the measurement and evaluation, planning of when the work to be done, determining how to use

\footnotetext{
*CONTACT: Ahmet Oğuz Akçay $\bigotimes$ aoguzakcay@gmail.com $\equiv$ Eskişehir Osmangazi University, Faculty of Education, Department of Elementary and Early Childhood Education, Eskisehir, Turkey
} 
the obtained data, and encouraging participation of students in classroom works (Özenç \& Çakır, 2015). Kampen (2020) stated that there are six types of assessments: diagnostic, formative, summative, ipsative, norm-referenced, and criterion-referenced assessments; however, teachers usually use summative and formative assessment methods only in their classroom. Bhat and Bhat (2019) defined summative assessments as assessment of learners that has a main goal of measuring the outcome of a curriculum. They are used to evaluate learning level, skill acquisition and achievement level of an intervention, which can be a project, course, workshop, program, or an academic year. Formative assessment is part of instructional process, and it is used to get accurate feedback about students' learning during the teaching process and to arrange teaching methods. In addition, the formative assessment focuses on organizing and improving students' learning in the process, helping students find the answer to the question, "How do I learn?" Exit slips, projects, homeworks, question-answer technique, summarization, concept maps, quizzes, criteria and goal setting, observations, self and peer assessment, and student record keeping are some of the instructional strategies that can be used for formative assessment (Kampen, 2020).

Peer assessment is one of the methods that use constructivist approach, where the student is responsible for his/her own learning and the teacher plays the role of a guide or facilitator/organizer of activities who support the student rather than being a transferrer of knowledge in the teaching-learning process. In the constructivist approach, the teacher is expected to use different methods, techniques, and technologies to assist students in structuring information, as well as various assessment and evaluation tools to enhance their learning and understanding (Şahin \& Kalyon, 2018). Hence, measurement and evaluation have a very important role for students' learning. An alternative assessment measures applied proficiency instead of student knowledge. Portfolios, project work, and other assessments that require a form of rubric are typical examples of alternative assessment (Bradley, 2020). Self-assessment and peer assessment are also types of alternative assessment. Self-assessment is the process where students make evaluations about their own learning and products (Brown \& Harris, 2014). Peer assessment methods are widely used in classrooms. Peer assessment is the process of providing formative or summative feedback to their peers about their work (Chin, 2007). In the peer assessment, one or more individuals in a group evaluate their peer(s) and students take responsibility for peer assessment and actively participate in the learning process. Students evaluate their peers' work and performance using pre-defined criteria. Moreover, students see each other as resources for understanding and checking quality work against previously established criteria (Garrison \& Ehringhaus, 2007).

While there might be some classroom management issues during the implementation of peer assessment, there are important advantages of peer assessment such as installing autonomy in learners, empowering learners in a learning environment, developing learners' confidence in assessment through practice, activating learners on self-evaluation and reflection, greater understanding of what is required by teachers in assessment, creating an interactive classroom environment, improving information and understanding, providing a clear and open marking system, and creating an effective way to assess a large amount of students' work and provide specific feedback (Langan \& Wheater, 2003),

As with all the other assessment methods, peer assessment also has its own disadvantages. The main disadvantage of peer evaluations is the non-objective evaluation of peers due to personal relationships and peer pressure. Moreover, it is really hard to keep the reliability and validity of peer assessment at an acceptable level (Ashenafi, 2019). Ashenafi (2019) also sees validity and reliability issues of peer assessments as a barrier for teachers to implement this strategy more often. Peer pressure and the possibility of affecting personal relationships are especially common in traditional evaluations, and they are barriers to implement peer evaluation method. 
On the other hand, with the advancements in educational technologies, teachers can use online peer assessment methods to avoid barriers that exist in traditional peer evaluation methods.

We are living in the technology era, so web-based or online peer assessment is also valuable to inform learners about their learning. While there are similarities between traditional and online peer assessment methods, there are also some differences. In both peer assessment methods, students assess their peers and provide feedback based on a rubric or a pre-defined standards. Students provide face-to-face feedback and assessment in traditional peer assessment, which may affect the quality and objectivity of the assessment because of the relationships between students. On the other hand, online peer assessment is made through web 2.0 tools and smartphone apps that anonymize students' names; thus, students can provide objective feedback because they do not feel any pressure from other students. Wen and Tsai (2008) stated the importance of online peer assessment in helping the learner pursue learning. Falchikov (2001) highlighted the importance of online peer assessment as,

In peer assessment, members of a class grade the work or performance of their peers using relevant criteria ... In peer feedback, students engage in reflective criticism of the work or performance of other students using previously identified criteria and supply feedback to them ... In peer learning, students learn with and from each other, normally within the same class or cohort ... (pp. 2-3).

Moreover, students take responsibility for peer assessment and participate actively in the learning process (Ndoye, 2017). This is valid for both traditional and online peer assessment methods. It is well-known that students like to use their phones in classroom activities. Online peer assessment can be done through web 2.0 tools and smartphone apps so that students are eager to participate in assessment processes with their devices. Online peer assessment tools enable students not only to grade their peer's work but also to provide feedback. These features are easily applicable in traditional peer assessment but some tweaking is required to utilize these features in online format. Online peer assessment tools also anonymize student names that removes peer pressure while assessing peer's work. This is very hard in traditional peer assessment. The goal of this study is to analyze traditional peer evaluation and online peer evaluation based on students' views.

\section{METHODOLOGY}

Qualitative research method was used in this study to understand pre-service teachers' opinions on different peer evaluation techniques. Qualitative research seeks to understand phenomena in context-specific settings, such as "real world setting [where] the researcher does not attempt to manipulate the phenomenon of interest" (Patton, 2002, p. 39). qualitative research is to explore human behaviors within the natural context in which it occurs (Hatch, 2002) and to focus on process and meaning (Merriam, 1998). Hence, the study investigated the opinions of the participants derived from their experiences within the context of a semester-long class.

\subsection{Participants}

The study was carried out in a public university in Turkey. The sample consisted of 58 second year pre-service teachers (45 girls, 13 boys) majoring in primary school teacher program who enrolled in the "Instructional Technologies and Material Development" course. Pre-service teachers were divided into 11 groups, with five or six students in each group. Participation was voluntary and the students in each group actively participated in the traditional and online peer assessment activities. Among the participants of the study, six students who worked in different groups were randomly selected in order to conduct the semi-structured interviews. 


\subsection{Peer Assessment Procedure}

The aim of the" Instructional Technologies and Material Development" course is to introduce the characteristics of various instructional technologies, their importance and use in the teaching and learning environment, the development of instructional materials, and the evaluation of materials of varied qualities. The instructional process of this course was organized with instructional methodologies and instructional materials. In this course, pre-service elementary teachers were asked to prepare materials based on given primary school level's standards. The teacher candidates prepared their materials in groups. In the evaluation process that lasted for six weeks, the groups presented the materials they prepared while the other groups evaluated the presenting group according to the given criteria: (1) expediency, (2) educational and pedagogical value, (3) promoting motivation and engagement, (4) user friendliness, (5) robustness and durability, (6) portability, (7) adaptability, and (8) design based on material principles. Each group can receive one to three points (low, medium, high) for each criterion, and the maximum total score a student can get was 24 points. The course was conducted face to face, but the evaluation process was implemented as one week face to face and one week online respectively during the six weeks. In addition, each group was required to give an oral presentation in class and upload pictures and videos of materials they prepared for the online platform.

\subsection{Data Collection Tools}

Data can be obtained from different sources, like observations and interviews, in qualitative research method (Yıldırım \& Şimşek, 2011). The data collection tools in this present study include online assessment forms (OAF), observations and semi-structured interviews. Students were required to develop an instructional material that can be used to teach a curriculum standard. Students presented their materials to the whole class. In OAF, students were asked to give a grade for their peers' material based on pre-defined evaluation criteria and write comments if they desire. Students' identities were kept anonymous in online peer assessment activity. Only instructors were able to see peer grades. Instructors also observed students in face-to-face peer assessment and online assessment activities. For semi-structured interviews, six open-ended questions were asked to six students to deeply understand the differences between traditional peer evaluation and online peer evaluation.

\subsection{Data Analysis}

Content analysis method was applied in the analysis of the data. In this process, the categories and themes that emerged with the coding of the data were interpreted. In this study, content analysis was used in four stages of processing qualitative research data from documents: 1) coding of the data, 2) finding themes, 3) editing codes and themes, and 4) identification and interpretation of the findings (Yıldırım \& Şimşek, 2011). Miles and Huberman (1994) explained how to provide intercoder reliability as follows: "Check coding not only aids definitional clarity but also is a good reliability check...The best advice here is for more than one person to code, separately" (p. 64). The coding data process was completed by three researchers separately to determine whether reliability and consistency were achieved. The congruity among these three code sets were higher than $80 \%$. Also, the interview and observation data were examined to see if they supported each other to improve the validity and reliability of the study (Yıldırım \& Şimşek, 2011). In order to support or disprove the validity of the analysis process, codes that appeared within one data source were considered with other data sources, effectively triangulating the code against multiple data sources. Additionally, the level of transparency was increased by providing rich and thick descriptions that allow readers to draw their own conclusions. 


\section{RESULTS}

The themes that emerged as a result of the analysis of the data collected within the study were (1) objectivity, (2) evaluation criteria, (3) interaction, and (4) attributions of the online evaluation platform. Theme and code list used in the research are shown in Table 1.

Table 1. Theme and Code List.

\begin{tabular}{ll}
\hline Themes & Code \\
\hline \multirow{3}{*}{ Objectivity } & - The effect of personal relationships on peer review \\
& - The effect of the anonymous answering system \\
& - Consistency in evaluation \\
\hline Evaluation criteria & - Evaluation criteria \\
\hline & - Peer pressure \\
Interaction & - Instant interaction \\
& - Face-to-face communication \\
\hline Attributions of the online & - Positive attributions \\
evaluation platform & - Negative attributions \\
\hline
\end{tabular}

\subsection{Objectivity}

\subsubsection{The Effect of Personal Relationships on Peer Review}

When the data collected from the participants of the study were examined, objectivity emerged as one of the points underlined primarily. Participants insistently emphasized their advantages and disadvantages in terms of objectivity in the online evaluation processes. Unfair evaluation was discussed by many participants in different ways. For example, they stated that due to the competition among the participants, they gave one another lower scores than usual and it negatively affected the fairness of the evaluation.

Other groups were unfair. This is because they want the highest score for their group (OAF). It was unfair because some of them deliberately gave high scores to other groups. Others deliberately gave low scores to other groups just to be the winner (OAF).

Some groups gave high scores for other groups if they have given them high regardless of whether the material met the criteria (Interview-Student 2).

Another participant argued that competition among students poses an obstacle to the fairness of students.

We can say that these evaluations depend on the conscience of the group members. I don't think everyone is fair. Sometimes they are competitive and not fair $(O A F)$.

Some friends gave low scores to other groups in order to be the first (Interview-Student 5)

Another point that should be emphasized under the theme of objectivity is that the participants do not find themselves and their friends ready for peer assessment. Many participants stated that during the evaluation, the students gave unfair scores by being negatively affected by the criticism.

The evaluations were absolutely unfair. Negative reviews and low scores were given against the negative reviews. To get higher scores, the materials were evaluated less than their value $(O A F)$.

One of the emphases that came to the fore in the point of objectivity was the highlight of friendships in the assessment. While the participants stated that good friends gave each other high scores, they also thought that their friends may be offended when they gave low scores. 
I mostly think about that problem. I was torn between giving low scores or taking risk to offend my friends by giving them low scores. But still, I tried to be fair while giving scores (OAF).

Another point that drew attention to objectivity in the evaluation was that each group attempted to perform a fair evaluation process by giving the same points given to them or by giving a similar score to all groups. On the other hand, this approach has been severely criticized by the participants. For example, one of the participants stated that the same points they gave to the groups were given to them, so the teacher evaluation would be more accurate than the peer evaluation.

I do not think it is a fair evaluation by any means. Each group gave us the same score that we gave them. No group's material reviews were fair. It would be more appropriate for the teacher to evaluate it, not the students $(O A F)$.

\subsubsection{The Effect of the Anonymous Answering System}

While participants highlighted the role of personal relationships in the evaluation process, they pointed to the anonymous evaluation feature in the online evaluation platform as a solution to this. Accordingly, many participants shared that they did not feel peer pressure during the evaluation process, and they performed their evaluations more comfortably. Therefore, the groups who did not see the scores given to them defended that they gave the other groups the points they deserved.

Online environment was more effective because nobody felt under pressure when evaluating or we didn't think like "the other group gave me this and I'll give the same score" (OAF).

Since we did not see who gave us how many points, we gave them the points we think they deserve $(O A F)$.

It was stated that anonymous evaluation not only provides objectivity but also enables the participants to carry out more comfortable evaluations, wherein the participants share their opinions more freely and comprehensively. Another important point emphasized by the participants was that the anonymous answering system ensures confidentiality between the teacher and the student. In this way, it was demonstrated that the participants performed a fairer and honest assessment.

Online environment. Because the answers and thoughts of the people remain confidential between the teacher and the student. Questions can be answered more honestly and undoubtedly $(O A F)$.

It was observed that students gave more honest answers in the anonymous evaluation, because the students knew that their score was only visible to the instructor (Observation).

According to the participants, another advantage of the anonymous evaluation is to prevent conflicts and communication problems that may arise in the classroom as a result of negative evaluation. In this way, it was shared that the participants were able to make negative evaluations for their friends without worrying about any trouble.

Online environment is more appropriate in this regard because it is not appropriate to use a hard language in the classroom while criticizing a material. If it is not liked, it should be expressed appropriately, but thanks to this application, low scores can be given as desired $(O A F)$.

While the participants highlighted many advantages of anonymous evaluation, some stated that keeping the identities hidden during the evaluation process could negatively affect the objectivity of the evaluations.

I think face-to-face evaluation is more objective because people gave random points as anyone didn't see what score he/she got in the Online environment (OAF). 
Similarly, most of the participants stated that the social pressure felt in face-to-face evaluation contributed positively to the objectivity of the evaluations. Thus, the participants emphasized that face-to-face interaction-based evaluation is much fairer and more realistic compared to the anonymity feature of the online evaluation system.

Ifind the face-to-face assessment more objective and realistic because, in Online environment, undeserved scores can be given because people give scores over the internet, it is difficult to control this $(O A F)$.

Finally, the participants stated that the evaluation process could not be carried out regardless of the evaluation environment and method, and they identified the competition among students as the main reason for this.

Neither of them was objective. Because my dear classmates gave low scores to everyone as if they were in the competition program $(O A F)$.

I don't think they are objective in either of them, because everyone scored low each other to be 1 st and no one's work was taken into account (OAF).

\subsubsection{Consistency in Evaluation}

One of the important points that emerged in the opinions of the participants about objectivity was the inconsistencies they observed during the evaluation process. In the evaluation of the same material, the score differences obtained from different groups emerged as an important criticism in this process. As can be seen from the examples given below, when the participants examined the scores given to themselves and the other groups, they emphasized that the differences between the scores were much higher than they should have been.

When we talked with the other groups after the lesson, we realized that the score ranges are very high $(O A F)$.

There were huge differences between the points. I think any criteria was not considered (OAF).

We have seen unbalanced score distributions $(O A F)$.

When one group gave 30 to a material and another group gave 12 to the same material, it shows the incompatibility clearly $(O A F)$.

The inconsistencies that emerged during the evaluation process were compared to the questionnaires filled without reading, and it was underlined that the evaluated material was not even considered in the evaluation.

I think there was no consistency. Scoring was sometimes very irrelevant, like a survey or scales filled out without reading (OAF).

\subsection{Interaction}

\subsubsection{Peer Pressure}

Participants emphasized the pressure in many points while examining the evaluation process. Some participants stated that the environment in which the assessment was made turned into a place where people could not express their opinion freely because of their friends who did not accept criticism. They even shared that commending one another can develop good relationships, while giving negative comments can develop a negative perception toward friends.

It depends on the person. Of course, I am not afraid to rate the person who can accept criticism, but the person who cannot take it must learn to accept criticism (OAF).

While criticizing, I realized that nobody could express their opinions freely and they just made good comments to be good with their friends $(O A F)$. 
Giving points in a classroom setting can strain the student or think negatively towards people who make a negative assessment (OAF).

\subsubsection{Instant Interaction}

One of the points considered as indispensable by the participants in the peer assessment was instant interaction. While the instant interaction was emphasized, some of the participants stated that online evaluation provided this better and the others think that face-to-face evaluation provided the instant interaction. For example, one of the participants thought that a more effective evaluation process was carried out because they had the opportunity to instantly convey their criticism in face-to-face evaluation.

I think face-to-face evaluation was more effective because we were able to criticize each other instantly and it became more effective (OAF).

Another participant argued that online assessment practices are much more effective as they offer the opportunity to interact instantly, regardless of location.

When an online assessment application that can be applied simultaneously inside or outside theclass is finished, we have the chance to receive reports instantly based on class, student or question $(O A F)$.

\subsubsection{Face-to-face Communication}

In addition to demonstrating the advantages of the online evaluation, the participants frequently emphasized the importance of face-to-face interaction during the evaluation process. Underlining the effectiveness of face-to-face interaction, the participants stated that people can express themselves more clearly and comprehensively by face-to-face interaction. Also, it has been added that more spontaneous interaction can be achieved through face-to-face communication.

The assessment was more effective when it was face to face. Above all, the basic elements of communication are gestures and facial expressions. The realization of interpersonal interaction while evaluating is a necessary skill for us as a teacher candidate. We can measure the reactions of people face to face more easily $(O A F)$.

In fact, instead of explaining here, I think it will be in the heat of the moment and more realistic, maybe I could not express myself here as I want (OAF).

Another reason for the participants to prefer face-to-face evaluation over online evaluation was the direct interaction of the people who evaluated and were evaluated during the face-to-face communication process. It is said that if the assessor is known, assessments can be taken more seriously, and due to the pressure to respond, it may be necessary to think about feedback.

Face to face evaluation, because we can see who is saying the mistakes, we can decide whether they are realist enough to be considered $(O A F)$.

Face to face evaluation. Because the assessed person or the assessors see the answer given, the obligation to give a more logical answer is felt $(O A F)$.

One of the important points mentioned by the participants is that people evaluated during the face-to-face evaluation both defend themselves and realize their deficiencies with more concrete feedback.

I think face-to-face was more effective because at that time we had the opportunity to defend the material we prepared and at the same time see our deficiencies (OAF).

\subsection{Evaluation Criteria}

Another theme that emerges as a result of the analysis of the data is the evaluation criteria. While the participants stated that they have many different criteria, they emphasized that these 
criteria strongly affect the evaluation. When the evaluation criteria are examined, one of the most prominent criteria is related to the extent to which the material meets the targeted gains. Therefore, one of the main criteria determined by the participants was suitability for the gains.

Which gains the material is made and its suitability to this gain, the usefulness of the material $(O A F)$.

The clear criteria helped us to evaluate the materials objectively (Interview-Student 3).

Another point emphasized by the participants in the evaluation criteria was the usefulness of the developed products. Many of the participants stated that they evaluated the materials by prioritizing their usefulness and functionality.

I tried to give points by paying attention to all evaluation criteria. Mostly, I paid attention to usefulness $(O A F)$.

In particular, I evaluated the materials according to whether they are useful in primary education (Interview-Student 6).

Another point that stood out in the evaluation criteria of the participants was the presentation of the material. The participants who evaluated the presentations as a kind of marketing method argued that the features the groups highlighted during the presentation were considered more important by the evaluators, and this directly affected the evaluation process.

Besides, some participants stated that instead of focusing on a single aspect of the materials they evaluated, they could approach the evaluation process more fully with a rubric developed in line with the material evaluation criteria. They stated that at the end of the process, the rubric used for evaluation provided a strong argument for the evaluator to justify that s/he evaluated correctly and thus provided a fair evaluation.

Although the groups determined certain criteria and made their evaluations according to the given criteria, some of the participants shared that they made their evaluations based on the evaluations of other groups. Therefore, it is possible to say that there are situations in which participants are affected by others in their evaluations. For example, some of the participants stated that they carried out their evaluations by averaging the scores given by other groups so that they would not affect the overall evaluation positively or negatively.

We have divided the number of points determined by everyone by 10 and divided it into our group number and said the result. That's exactly how we decided $(O A F)$.

We calculated the points given by each group member separately and scored them by taking the average $(O A F)$.

\subsection{Attributions of the Online Assessment Platform}

As the participants were not familiar with conducting an evaluation process online, they shared positive and negative thoughts when asked for their opinions about this process.

\subsubsection{Positive Attributions}

In this context, the positive feature the participants highlighted is that the evaluation process, which is carried out via mobile phones, can be carried out anytime and anywhere independent by the requirements of the age. The participants who argued that the notifications received through the application are valuable in terms of carrying out the process in a timely and effective manner said that the communication with the one responsible of the course and other students who took the course through this platform made the process more efficient. Thanks to this platform, the participants had constant access to their products and their friends' products.

I think it has a lot of advantages. Using the application, getting information about the course and seeing the homework of our other friends is an advantage (OAF). 
I could follow the assignments all the time and I had access to the assignments everywhere $(O A F)$.

The participants who underlined that this evaluation platform is always with them because it is a mobile application stated that it is a great convenience to upload and access this platform via mobile phones instead of carrying and sharing products and materials with them.

It is more advantageous to submit assignments in the online environment because we have been freed from carrying materials constantly $(O A F)$.

Another feature highlighted by the participants is that with this evaluation platform, all products and materials prepared by the whole class became a portfolio that is available for future use.

It is very useful. The assignments that we uploaded there will be useful for us in the future $(O A F)$.

In addition, as we uploaded our assignments to the online platform, we were able to access the materials other friends made (Interview-Student 4).

\subsubsection{Negative Attributions}

The participants highlighted not only advantages but also disadvantages of the online evaluation platform. Some of the participants stated that they are not yet fully prepared for this technology, as they encountered difficulties in trying it for the first time.

I do not think we are fully ready for applications made on the internet. We need to improve on this $(O A F)$.

On the other hand, some of the participants shared that they got used to the application over time and that they did not experience any problems related to use.

At first, I thought it was a difficult application but with time, I got used to it. Easy and simple application $(O A F)$.

The technical difficulties, including internet problem, encountered during the use of the evaluation platform were also regarded as disadvantages. Many of the participants stated that they could not use the platform efficiently enough because they did not have enough quality internet access. Also, they shared that the mistakes made while using the phone screen are troublesome.

Since we made the scoring on the phone, touching accidentally sometimes caused trouble, and I think it was difficult to log in separately for each scoring (OAF).

Some of the students had problems connecting to the internet. In addition, students whose phones were old could not use the program as they wanted due to freezing of the screens during the evaluation process (Observations).

\section{CONCLUSION}

This study aimed to compare traditional peer evaluation and online peer evaluation in order to investigate which method is more effective in peer assessment strategy. The results of the study showed that students make more objective peer evaluation when online assessment tools are used in comparison to traditional tools. Students' identity was not known during the online peer evaluation process, so students expressed their opinions liberally in online assessment since they did not feel any pressure from their peers. Anonymity, on the other hand, was not possible during the face-to-face assessment. Therefore, online assessment provided more advantages than traditional methods in terms of anonymity of the students and objectivity of the peer evaluations. However, the study also found some disadvantages of assessing their peers in an online format. Students mentioned the difficulty of writing in handheld devices and not having the internet on their devices when using online tools. While it is easy to conclude that teachers 
and instructors should implement online peer evaluation methods in order to have an effective feedback mechanism, they also need to keep in mind that students may not be able assess their peers in depth due to challenges of handheld devices and lack of internet on their devices.

The study revealed that students find the online peer assessment environment as a way that enables them to express their opinions objectively. Based on the results of the research, objectivity has emerged as one of the most emphasized points. In a similar context, Kali and Ronen (2005) expressed different arguments. Kali and Ronen (2005) found that there were differences between student and instructor scores; students were not objective in evaluating their peers since they had bias based on personal stand. In addition, according to Herbert (2007), some students did not make an objective evaluation when evaluating their peers. Since this study allowed the participants to compare face-to-face and online evaluation processes, participants found the online evaluation process relatively objective. Therefore, this study reached conclusions different from the literature.

This study demonstrated that the well-organized criteria help pre-service teachers evaluate their peers objectively and systematically. The statements under the evaluation theme provided that the students were more able to approach the evaluation process comprehensively. Also, following the criteria helped them evaluate their peers' materials in a more objective manner. Similar results were found by Chen and Tsai (2009); they mentioned that explained criteria help the instructor to maintain students' attitudes toward the class. It can be concluded that whether it is online peer assessment or traditional face-to-face assessment, pre-defined criteria for evaluation help students make accurate evaluations.

Another highlighted point in this research is the importance of interaction. Students cannot interact with each other in online assessment environments. However, although face-to-face evaluation methods enable interaction among students, pre-service teachers stated that peer pressure may be common in face-to-face evaluation. Hence, the anonymity in the online environment allowed the students to interact with their peers better. Tsai, Lin, and Yuan (2002) identified that students can freely express their thoughts about their peers' work in online peer assessment. McConnell (2002) also finalized similar results and stated that utilizing online peer assessment can furnish students with a mysterious domain to unreservedly communicate their considerations and thoughts regarding others' work.

To summarize, the students were asked to evaluate the materials prepared by their peers as a group. In this context, the opinions of students about online and face-to-face evaluation were taken. Within the scope of this aim, interviews, observation, and online assessment forms data obtained from participants in this study revealed the positive attitudes towards online peer assessment[A1]. The result of the study indicated that students evaluated their peers more objectively online than face to face. Further studies are needed to investigate online peer assessment practices in various aspects. The study recommends that a combination of peer and instructor assessment and even self-assessment can give a better validity of the peer assessment[A3] . Since this study focused on the use of a particular online peer assessment tool, the effectiveness and ease of use affected students' peer assessment experience. The advancement in web 2.0 tools generated various tools for online peer assessment. Therefore, further studies can investigate the effects of various peer assessment tools. The study was conducted with pre-service elementary teachers that took several assessment and evaluation courses; thus, it may be easier to integrate assessment strategies with education faculty students but not with other departments. Lastly, the study found advantages and disadvantages of online peer assessment but with some training for instructors and students. Online peer assessment strategies can be a useful method, especially during Covid-19 pandemic. 


\section{Declaration of Conflicting Interests and Ethics}

The authors declare no conflict of interest. This research study complies with research publishing ethics. The scientific and legal responsibility for manuscripts published in IJATE belongs to the author(s).

\section{Authorship Contribution Statement}

Ahmet Ŏguz Akçay: Investigation, research design, literature review, data collection, data analysis, and writing the manuscript. Ufuk Güven: Research design, literature review, methodology, and writing the manuscript. Engin Karahan: Research design, methodology, data analysis, and writing the manuscript.

\section{ORCID}

\section{Ahmet Oğuz Akçay (D) https://orcid.org/0000-0003-2109-976X \\ Ufuk Güven (iD https://orcid.org/0000-0003-1977-6426 \\ Engin Karahan (D) https://orcid.org/0000-0003-4530-211X}

\section{REFERENCES}

Ashenafi, M. M. (2019). Online peer-assessment datasets. Preprint. https://arxiv.org/pdf/1912 $.13050 . \mathrm{pdf}$

Bhat, B. A., \& Bhat, G. J. (2019). Formative and summative evaluation techniques for improvement of learning process. European Journal of Business \& Social Sciences, 7(5), 776-785.

Boud, D., \& Falchikov, N. (1989). Quantitative studies of student self-assessment in higher education: A critical analysis of findings. Higher Education, 18(5), 529-549.

Bradley, B. (2020). Using alternative assessment. https://ctl.byu.edu/using-alternativeassessments

Brown, G. T. L., \& Harris, L. R. (2014). The future of self-assessment in classroom practice: Reframing self-assessment as a core competency. Frontline Learning Research, 3, 22 30. https://doi.org/10.14786/flr.v2i1.24

Chen, Y-C., \& Tsai, C. (2009). An educational research course facilitated by online peer assessment. Innovations in Education and Teaching International, 46, 105-117. https://doi.org/10.1080/14703290802646297

Chin, P. (2007). Peer assessment. New Directions in the Teaching of Physical Sciences, 3, 1318. https://doi.org/10.29311/ndtps.v0i3.410

Davies, P. (2002). Using students reflective self-assessment for awarding degree classifications. Innovations in Education and Teaching International, 39(4), 307-319. https://doi.org/10.1080/13558000210161034

Dochy, F., Segers, M., \& Sluijsmans, D. (1999). The use of self-, peer, and co-assessment in higher education: A review. Studies in Higher Education, 24(3), 331-350. https://doi.org/10.1080/03075079912331379935

Duran, M., Mihladiz, G., \& Balliel, B. (2013). İlköğretim öğretmenlerinin alternatif değerlendirme yöntemlerine yönelik yeterlilik düzeyleri [Adequacy levels of primary school teachers towards alternative assessment methods]. Mehmet Akif Ersoy Üniversitesi Ĕ̈itim Bilimleri Enstitüsü Dergisi, 2(2), 26-37.

Falchikov, N. (1995). Peer feedback marking developing peer assessment. Innovations in Education and Training International, 32, 175-187. https://doi.org/10.1080/13558009 $\underline{50320212}$

Falchikov, N. (2001). Learning together: Peer tutoring in higher education. Routledge Falmer. 
Garrison, C., \& Ehringhaus, M. (2007). Formative and summative assessments in the classroom. http://ccti.colfinder.org/sites/default/files/formative and summative asse ssment in the classroom.pdf

Hatch, A. J. (2002). Doing qualitative research in education settings. State University of New York Press.

Herbert, N. (2007, January). Quantitative peer assessment: Can students be objective?. In Proceedings of the Ninth Australasian Conference on Computing Education-Volume 66 (pp. 63-71). Australian Computer Society, Inc.

Kali, Y., \& Ronen, M. (2005, May). Design principles for online peer-evaluation: Fostering objectivity. In Proceedings of the 2005 Conference on Computer Support for Collaborative Learning: Learning 2005: The next 10 years! (pp. 247-251). International Society of the Learning Sciences.

Kampen, M. (2020). The 6 type of assessments. https://www.prodigygame.com/mainen/blog/types-of-assessment/

Langan, M.A., \& Wheater, C.P. (2003). Can students assess students effectively?. Some insights into peer assessment. Learning and Teaching in Action, 2(1). https://www.cel t.mmu.ac.uk/ltia/issue4/langanwheater.pdf

Linn, R. L., \& Gronlund, N. E. (1995). Measurement and assessment in teaching (7th ed.). Pentice-Hall Inc.

McConnell, D. (2002). The experience of collaborative assessment in E-learning. Studies in Continuing Education, 24, 73-102. https://doi.org/10.1080/01580370220130459

Merriam, S. B. (1998). Qualitative research and case study application in education. JosseyBass.

Miles, M. B., \& Huberman, A. M. (1994). Qualitative data analysis (2nd ed.). Sage.

Miller, L., \& Ng, R. (1996). Autonomy in the classroom: peer assessment. In R. Pemberton, eds. pp. 133-146.

Ndoye, A. (2017). Peer/Self assessment and student learning. International Journal of Teaching and Learning in Higher Education, 29 (2), 255-269.

Özenç, M., \& Çakır, M. (2015). Sınıf öğretmenlerinin alternatif ölçme ve değerlendirme yeterliklerinin belirlenmesi [Exploring primary school teachers' competencies of alternative assessment and evaluation]. Elementary Education Online, 14(3), 914-933. http://dx.doi.org/10.17051/io.2015.22900

Patton, M. Q. (2002). Qualitative evaluation and research methods (3rd ed.). Sage Publications, Inc.

Roediger, H. L., Agarwal, P. K., McDaniel, M. A., \& McDermott, K. B. (2011). Test enhanced learning in the classroom: long-term improvements from quizzing. Journal of Experimental Psychology. Applied, 17(4), 382-95. https://doi.org/10.1037/ $\underline{\mathrm{a} 0026252}$

Şahin, M. G., \& Kalyon, D. Ş. (2018). Öğretmen adaylarının öz-akran-öğretmen değerlendirmesine ilişkin görüşlerinin incelenmesi [Investigation of preservice teachers' opinions about self-, peer- and teacher assessment]. Kastamonu Eğitim Dergisi, 26(4), 1055-1068. https://doi.org/10.24106/kefdergi.393278

Taras, M. (2005). Assessment-summative and formative-some theoretical reflections. British Journal of Educational Studies, 53(4), 466-478. https://doi.org/10. 1111/j.1467-8527.2005.00307.x

The National Council for Teacher Education [NCTE]. (2013). Formative assessment that truly informs instruction. http://www.ncte.org/positions/statements/formative-assessm ent/formative-assessment full

Topping, K. J. (1998). Peer assessment between students in colleges and universities. Review of Educational Research, 68(3), 249-276. https://doi.org/10.2307/1170598 
Topping, K. J. (2009). Peer Assessment. Theory into Practice, 48(1), 20-27. https://doi.org/10 $.1080 / 00405840802577569$

Tsai, C.-C., Lin, S.S.J., and Yuan, S.-M. (2002). Developing science activities through a networked peer assessment system. Computers \& Education 38, 241-252. https://doi.org/10.1016/S0360-1315(01)00069-0

Wen, M. L., \& Tsai, C. (2008) Online peer assessment in an inservice science and mathematics teacher education course. Teaching in Higher Education, 13, 55-67. http s://doi.org/10.1080/13562510701794050

Yildirim, A., \& Simsek, H. (2011). Sosyal bilimlerde nitel arastirma yontemleri (8th ed.). Seckin Yayinevi. 